\title{
Cavernous Haemangioma of the Parotid Gland in Adults: A Review of the Literature \& Case Report
}

\author{
Yousif I Eltohami ${ }^{1}$, Abeer H Alrofaey ${ }^{2}$ and Ahmed M Suleiman ${ }^{1}$ \\ ${ }^{1}$ University of Khartoum, Sudan \\ ${ }^{2}$ Al Neelain University, Sudan
}

Submission: November 15, 2018; Published: December 11, 2018

*Corresponding author: Yousif I Eltohami, Assistant professor of oral \& maxillofacial surgery, Faculty of dentistry, University of Khartoum, Sudan

\begin{abstract}
Cavernous Hemangioma of the parotid gland is an exceptionally rare pathology of the salivary gland in adults, with only about 50 cases reported globally \& a strikingly predominant female's presentation, and an observed left sided preference. We thereby report an unusual case of a 34 years old Sudanese male with $5 * 5 \mathrm{~cm}$ in diameter cavernous hemangioma affecting the right parotid salivary gland that started 6 years ago to alert surgeons to the possibility of such a lesion, which was diagnosed using MRA \& treated with Superficial parotidectomy using Modified Blair incision with initial ligation of external carotid artery \& facial nerve preservation , we describe the clinical course, explain the diagnostic approach, discuss the current treatment modalities and review the literature.
\end{abstract}

Keywords: Cavernous hemangioma; Vascular tumor; Parotid gland; Patrotidectmy; External carotid artery; Ligation

\section{Introduction}

Hemangiomas are benign vascular tumors characterized by increased proliferation and turnover of endothelial cells. Traditionally, they were categorized as capillary, cavernous and mixed [1-5], but so far only cavernous hemangioma is reported in adults [3-6].

Out of $6 \%$ of salivary gland neoplasms arising in the head and neck, $80 \%$ arises from the parotid gland \& among all parotid tumors $80 \%$ are benign [4]. $65 \%$ of all hemangiomas are in the head and neck region, they can affect the skin, muscles \& salivary glands $[7,8]$ But, they principally affect the salivary glands with the parotid gland as the most common site $81-85 \%$. They account for $0.4-0.6 \%$ of all parotid gland tumors, with $2 \%$ occurrence in adults vs. $50 \%$ in children first year of life $[1,8,9]$ Adult hemangioms center itself as one of the rarest presentations; with only about 50 cases reported globally [10] and constitute a distinct entity of parotid pathology that requires specific diagnostic tools and management.

Achache etal. [11] argued that the use of confusing terminology as physician still use the generalized term 'angioma' to describe both tumors and vascular malformations, had added more struggle to the insufficient diagnostic techniques, inadequately adapted treatments and poorly oriented research on hemangioma. They recommended the use of the international classification resulting from the $10^{\text {th }}$ Workshop of the International Society for the Study of Vascular Anomalies (ISSVA), held in Rome in 1996, which was based on clinical, evaluative, histological and hemodynamic elements [12].
It describes two large categories of vascular anomalies:

1. Proliferating vascular tumors (hemangiomas) and

2. Vascular malformations; 'immature' tumors, such as hemangiomas, which are observed in infants and, after a period of growth, eventually regress spontaneously; and 'mature' tumors, which do not regress, but continue to develop throughout life [11].

Recently, Hemangiomas are classified as benign vascular tumors, divided into infantile and congenital types, with further subdivision of congenital hemangiomas into No Involuting Congenital Hemangiomas (NICHs) and Rapidly Involuting Congenital Hemangiomas (RICHs) and partially involuting congenital hemangioma (PICHs) $[4,13]$.

Due to rarity of this condition in adults, clinical behavior may be quite misleading and less reported as they are rarely biopsied with hematoma formation risk. We thereby report on a typical presentation of cavernous hemangioma of parotid gland in an adult black male with right parotid gland cavernous hemangioma with emphasis on the clinical diagnosis and treatment challenges, aspiring to add into consideration Cavernous hemangioma as part of the differential diagnosis of parotid masses in adults.

\section{Case Report}

A 34 years old Sudanese male who is generally fit with no significant medical history \& no family history of interest, presented to oral and maxillofacial surgery clinic complaining from painless firm unilateral facial right side parotid region mass 


\section{Advances in Dentistry \& Oral Health}

presented six years ago and had since a slow progressive growth pattern gradually reaching the present size (with no history of sudden increase in size), patient denied any history of habits (smoking, snuff dipping or alcohols drinking).

Clinical examinations showed a non-tender soft in texture, freely mobile, firm with well-defined palpable margins, dome shaped swelling of $\left(5^{*} 5 \mathrm{~cm}\right)$ diameter with in the right parotid gland that raised the ear lobe the hollow below and behind the ear lobule was obliterated. with intact non ulcerated, normal overlying skin in color, texture \& temperature (no discoloration, no bruises nor pulsation), similar to the surrounding skin, without apparent discharge, scarring or any dilated blood vessels, the swelling did not show any change in size during meals, bending or straining nor did the patient state any change in size associated with weather changes. On palpation, it was neither hot nor had thrills or bruits (non-pulsatile) (Figure 1).

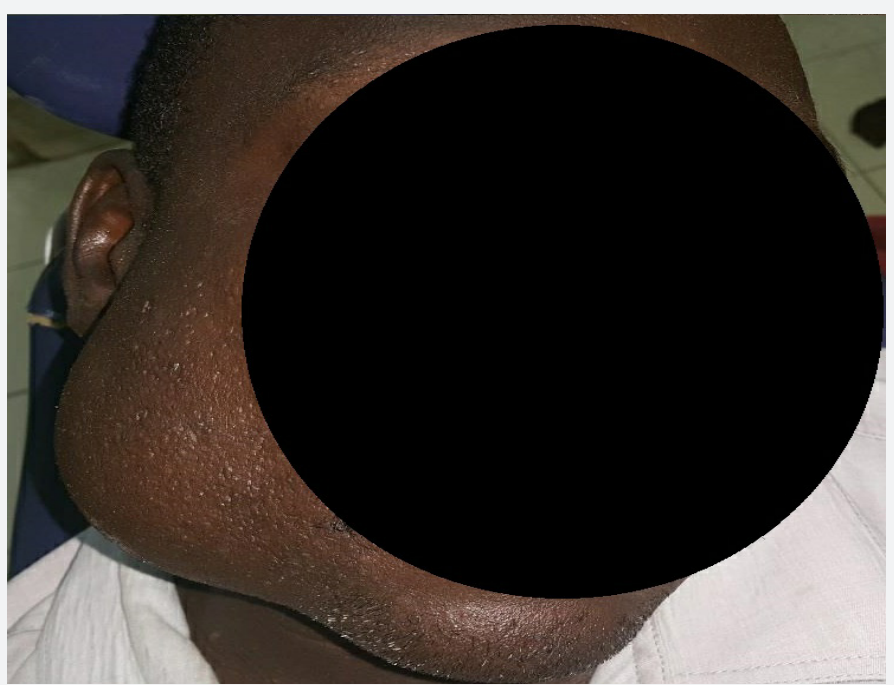

Figure 1: Shows $5^{\star} 5 \mathrm{~cm}$ in diameter firm dome shaped right parotid swelling raising the right ear lobe with intact normal colored skin.

On bending the head down, the size of the swelling increased in size 'turkey wattle' sign. On applying pressure over both external and internal jugular veins simultaneously the swelling in the parotid region became more prominent 'Reddi's Sign'.

The facial nerve terminal branches were intact bilaterally and symmetrical, patient shows no signs of numbness, facial paralysis or any abnormal sensation.

Intra oral examination revealed normal parotid gland duct (Stenson`s) opening, Normal mouth opening with poor oral hygiene, there was no apparent soft palatal swelling or deviation of the uvula excluding the deep parotid lobe and the parapharyngeal space involvement. Neither Cervical lymphadenopathy nor other masses.

Diagnostic approach; Fine needle aspiration cytology (FNA) was taken by experienced pathologist but the results were inconclusive, it revealed blood and epithelial cells. Magnetic Resonance Angiography (MRI) was performed which reported intense homogenous parotid mass with incorporation of terminal branches of the External Carotid Artery (ECA) as the feeding vessels (Figure 2).

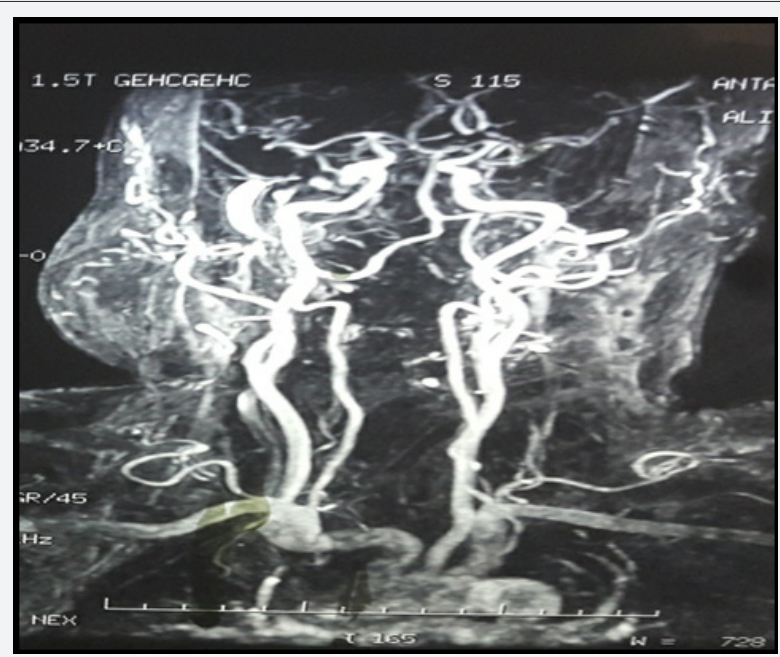

Figure 2: Diagnostic MRA showing intense homogenous parotid mass \& Revealing the terminal branches of the External Carotid Artery as the feeding vessels of this vascular tumor. 


\section{Advances in Dentistry \& Oral Health}

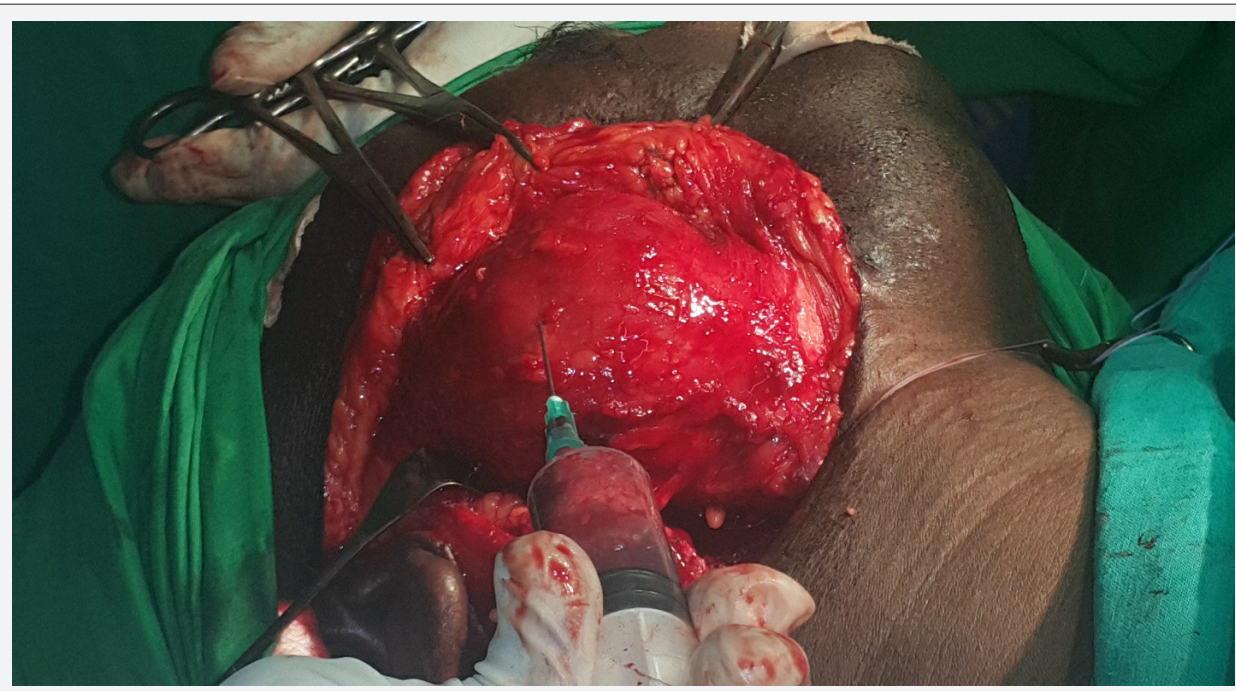

Figure 3: Intraoperative Appearance of the right parotid gland during the superficial parotidectomy using Modified Blair incision that Shows blood aspiration from the gland confirming the provisional diagnosis of intragland vascular tumor.

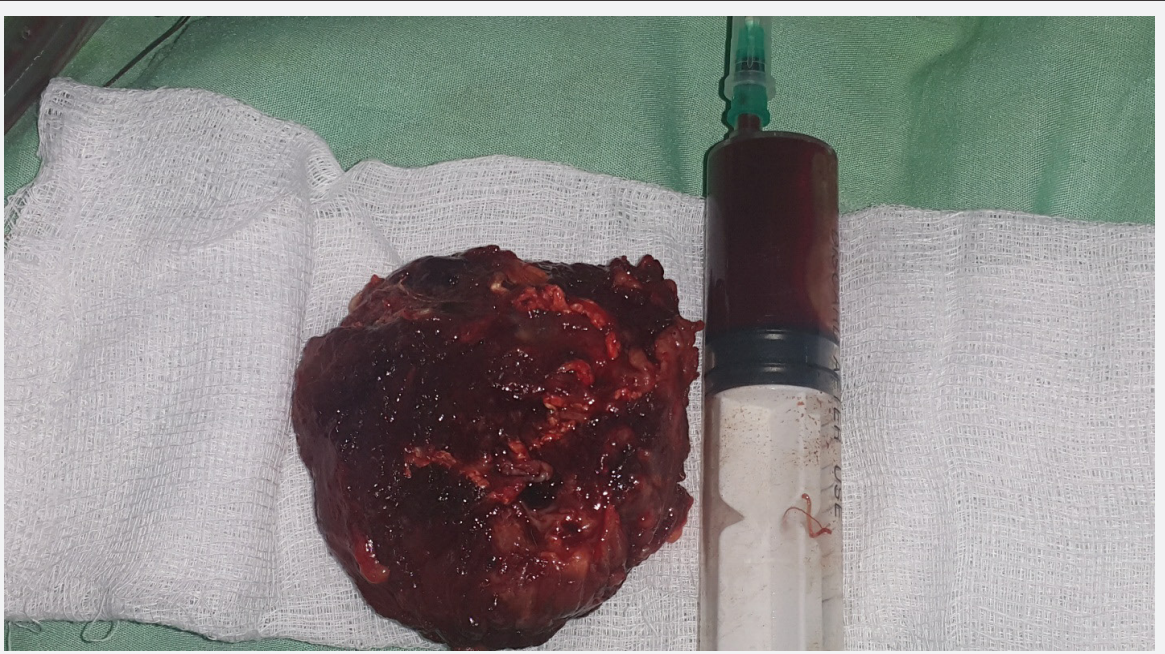

Figure 4: Shows the excised vascularized tumor specimen and the aspirated blood.

Diagnosis; our clinical, radiographic \& pathological impression favored vascular malformation or tumor of the right parotid gland surgery was carried out; initially ligation of External Carotid Artery (ECA)was performed followed by superficial parotidectomy using Modified Blair incision. The buccal branch of the facial nerve was pushed by the tumor, but it was identified \& preserved (Figure 3 \&4).

Postoperatively, a no facial weakness was noticed, Patient recovered well with regular follow up. The histopathological examination of the excised tumor confirmed cavernous haemangioma fully resected without neoplastic cells. At follow up; patient is currently asymptomatic, with no recurrence.

\section{Discussion}

To date, there is still not enough data regarding recent prevalence of parotid glands Cavernous Hemangioma presentation in adults. It considers extremely rare, with the 2005 WHO classification of tumors stated about 50 cases reported globally $[1,3,10]$, mostly as individual case reports, Since then only few cases have been described in the literature, \& the cavernous type is the only one described so far [4,6]. In general, vascular anomalies; tumors and malformations remain one of the least well understood entities encounter in clinical practice as there has been no animal model for studying the underlying pathological mechanism and developing therapeutic modules [11].

In contrary to the present case, the classical victim usually was: Female $[1,4,8,14]$ with $2: 1$ female to male ratio [3], it usually fluctuates in size with pregnancy and menarche. These phenomena suggest that the endothelial cells may be quite responsive to circulating hormones [15]. Where juvenile hemangioma, displays predominately in males [9]. With an observed Left-sided preference has been noted [16,17], in both parotid and submandibular gland cavernous hemangioma [15]. Haemangioma of major salivary gland especially parotid is quite common in pediatric population. Ninety percent of it arise in the first three decades of life and are the most common lesions of the major salivary glands during infancy and early childhood $[4,17]$. Few published studies have provided quantitative evidence of adult presentations of parotid cavernous hemangioma. 
Nagao et al. [16] in a series of 20 cases of cavernous heamangioma of parotid gland; where the average age was 26 years (range, 4 months to 50 years). Where in an analysis of all the major salivary gland lesions recorded at the Armed Forces Institute of Pathology (AFIP) found that $1.4 \%$ were benign mesenchymal tumors. Of this group, $30 \%$ were hemangiomas. They were more common in the parotid gland with $87.5 \%$ of all salivary gland hemangiomas in comparison with $12 \%$ in submandibular gland [18]. A probable explanation of this big incidence difference between parotid and submandibular is the lack of a well-defined capsule and the presence of neurovascular structure in the parotid gland which can be challenging in the surgical option of treatment $[17,18]$. A ten years retrospective study, among 614 parotidectomy performed between 1998 and 2008 at Chirurgie Cervico-Faciale institution, France; were 462 (75\%) had a total of 10 cases $(1.6 \%)$ of vascular malformations have been identified. There was a marked female predominance (90\%) as usual, there was no side predominance [11].

They also stated that there were no bilateral cases [11], which was also noted during the collection of this literature review. CC Chuange et al. [15] stated that More than $90 \%$ of cases present before the fourth decade of life. The average age of patients presenting with hemangiomas is 10 years (range, 2 months to 74 years) [15], However, cavernous hemangiomas typically occur in adolescents and adults, Adult salivary gland hemangiomas are of the cavernous type, while infantile hemangiomas are usually capillary $[15,19]$.

With this patient being an adult male in the fourth decade and a right-sided presentation we consider it an atypical presentation that showed be considered.

Histological presentation; The cavernous variant, as seen in this case, is characterized by dilated, thin-walled tortuous vascular spaces filled with blood and lined with flattened endothelial cells which sometimes may be thickened by adventitial fibrosis, calcificayion is also common $[3,4,6,15,20]$.

The classic clinical presentation of a parotid hemangioma is not very specific. It usually present as an asymptomatic slowly progressive, poorly defined, soft, firm compressible, mobile, painless swelling below and/or in front of the ear lobule [14] in the parotid region that is rarely associated or not with skin lesions characterized by red, red-bluish, or blue macules and/or papules, as well as a vibration or pulsation when palpating the parotid region $[1,3,4]$.

Although, it is very rare to observe bluish discoloration of the skin with cavernous hemangioma, which is a characteristic feature of benign hemangioendothelioma [21]. The tumor expands slowly but sometimes sudden increase in size can lead to compression of vital structures especially at later stage [22]. Invasion is commonly by continuity with complete or partial replacement of parotid tissue [4,22]. Symptoms; dyspnea or dysphagia, when present were related to either the longstanding nature of the tumor or its size [17]. The main complaint related is usually aesthetic. It may be associated with varying degrees of pain [23]. Deformity and severe pain depend on tumor size and the presence of intralesional bleeding or acute thrombosis [24]. Manual compression can be used to relieve pain and local edema if present [23].

Facial palsy as part of the clinical presentation has not been observed [19]. They tend to be larger and less well circumscribed than the capillary and juvenile hemangiomas [15]. Although they are typically slow flow lesions and may not be angiographically evident [17]. Cavernous hemangiomas in adults does not regress $[1,15]$, and they tend to have a chronic course and a slowly progressive growth unlike pediatric one $[1,25]$ The presence of radiological radio-opacities phleboliths is very suggestive of hemangioma or vascular malformation (cavernous hemangioma in particular) $[1,4,10,15,17,21]$.

Redid BR et al. [21] even stated that the presence of calcified phleboliths on radiological imaging is a characteristic finding of cavernous hemangioma of the salivary gland [26], although cavernous hemangioma with multiple phleboliths are very rare $[1,4,17]$. However, these only occur in $2-3 \%$ of cases and it should be differentiated from sialoliths and other cause of head and neck calcifications by a sialography $[1,4,10,25]$.

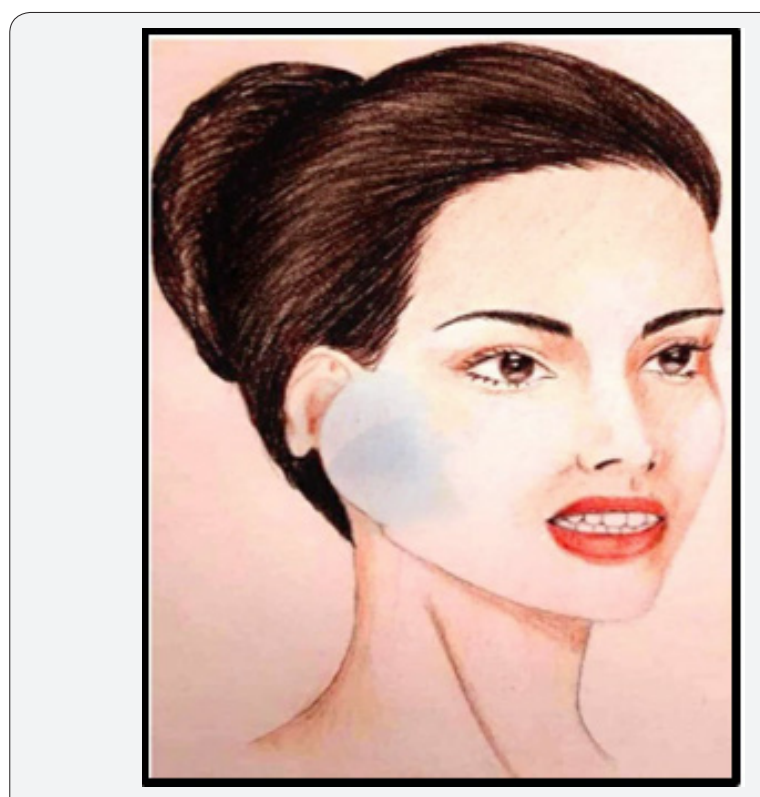

Figure 5: Drawing that represent Turkey Wattle Phenomena: pathognomonic manifestation where Tumor volume increases with active teeth-clenching or with dependent head positioning in Valsalva maneuver or when the head is tilted forward, or the patient lies flat, notice the bluish skin taint (macules) which is a rare presentation. Courtesy of Dr. Hiba Abdalhafeez.

The clinical examination to diagnose parotid hemangioma is Turkey-Wattle Sign. If the hemangioma lies outside the gland, there will not be any increase in the size $[4,10,21,22,27]$. Dempsey et al. [27] described this specific clinical sign, was found in $50 \%$ of their patients. Tumor volume increases with the Valsalva maneuver or when the head is tilted forward, or the patient lies flat [21]. For many years this phenomenon was surprisingly neglected by many examiners, but recently many had stated its importance and encouraged adding it to the parotid gland examination [10,21]. Petros Koltsidopoulos et al. [28] considered 
the phenomena an unusual pathognomonic manifestation in both intramassetric (intramascular hemangimoa present less than $1 \%$ of all hemangiomas [29] with $13 \%$ in head and neck region [30] \& are considered very difficult to diagnose) \& intraparotid hemangioma. It can be examined with active teeth-clenching (on contracting masseter muscle) or with dependent head positioning (when the head is bent forward, or the patient lies flat) [21,28-
32] but is usually more prominent with the masseter muscle contraction [21] (Figure 5).

The sign may be due to vascular engorgement within the lesion, which impedes venous return from the head to the superior vena cava. The name wattle comes from the red vascular structure in the neck of the male turkey that can increase in size when filled with blood [20].
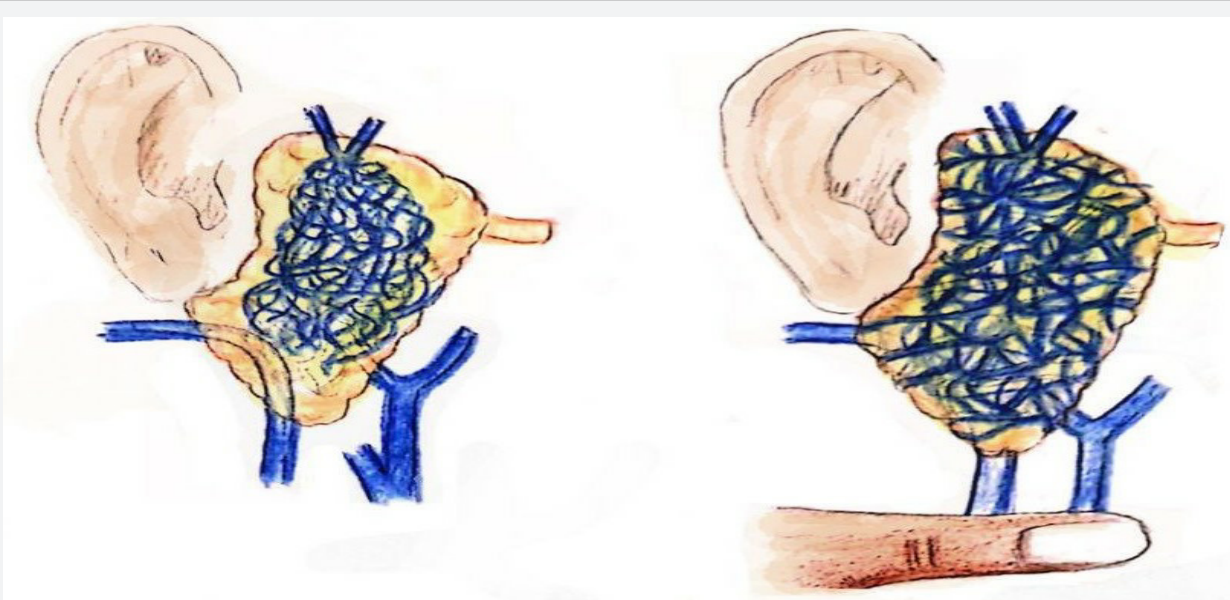

Figure 6: Drawing that represent Reddi's Sign : Diagnostic application of pressure over parotid venous outflow (both external and internal jugular veins) by placing the thumb of the opposite hand across them, careful to avoid carotid bulb massage or compression while infront of the patient with the neck muscles relaxed will cause the hemangioma to bulge stretching the parotid capsule with distended outlinesthus for making the outline of the gland clinically apparent . Courtesy of Dr. Hiba Abdalhafeez.

Reddi BR et al. [21] described an observation that can be used for diagnosis of parotid hemangioma, which we can address it as Reddi's Sign where hemangioma can be distented by blocking its venous outflow. If it is located within the parotid gland, it will stretch the parotid capsule. Thus, application of pressure over parotid venous outflow (both external and internal jugular veins) by placing the thumb of the opposite hand across them, careful to avoid carotid bulb massage or compression while in front of the patient with the neck muscles relaxed will cause the hemangioma to bulge stretching the parotid capsule with distended outlines. It makes the outline of the gland clinically apparent (Figure 6).

This observation is useful to differentiate a hemangioma present in the parotid gland from one that is placed outside the gland like an intramuscular hemangioma of the masseter muscle \&infratemporal fossa (where would not be any increase in size) [27] or internal jugular phlebectasia [33].

Unfortunately, this assumption must be tested on several patients if it were to be accepted as a valid clinical sign. Which shows some difficulty Considering the rarity of the [34] \& that may add to the delay in discovering this sign [21].

If these signs are absent the diagnosis could be challenging, particularly in an adult patient in whom this disease is usually not taken into consideration in the differential diagnosis of parotid mass. Therefore, recurrent mumps, tumors or cystic lesion of glandular origin or hypertrophy of the masseter muscle are the principal differential diagnosis. In adults, the pleomorphic adenoma and the Warthin tumor are within the most common benign tumors of salivary glands or sialolithiasis in case phileboths are presence $[1,4,10,14]$. Hereby, History and physical examination are elements supporting the diagnosis of probability $[1,24,35]$.

\section{Investigations}

The imaging techniques commonly used for investigation includes; Ultrasonography (USG), Computed Tomography (CT) scan, Magnetic resonance imaging (MRI) and Fine Needle Aspiration Cytology (FNAC). Ultrasonography is the first investigation of choice in salivary gland imaging $[4,10]$. On ultrasound, hemangiomas are heterogeneous hypoechgen lesions in which calcified phieboliths are identifiable [3].

MRI is regarded as the best imaging method for evaluation of parotid hemangioma and preferred over CT scan for the evaluation of soft tissue lesions in head and neck region $[1,4,8,10,20,36]$. It's the complementary examination of choice in their exploration, its useful in demonstrating lesions of the parotid region thus making it possible to suggest that the tumor is a hemangioma and for its extension to be studied $[1,3]$.

Hemangiomas generally appear as a lobulated lesion with a Ti -weighted image, hyper-intense on T2 signal with homogeneous enhancement and empty signal areas within the lesions $[1,3,37,38]$. It also helps determine the surgical approach for the tumor and to reveal its relationship with adjacent structures. [1,38].

Fine Needle Aspiration Cytology FNAC is useful in the preoperative diagnosis of tumors of the head and neck, so it's considered the final procedure for a definitive histologic diagnosis, but it is regarded unnecessary preoperatively in case of hemangioma because of risk of generating a hematoma and when MRI is highly 


\section{Advances in Dentistry \& Oral Health}

suggestive of the diagnosis $[1,4,8,10,38]$. Color Doppler Flow meter is also suggested to support diagnosis $[5,21,26]$.

Therefore, a typical clinical presentation and characteristic radiologic findings are enough for the diagnosis [1,38]. The histological findings reveal Large thin walled tortuous and dilated blood vessel, lined by flattened endothelial cells is a typical sign of cavernous hemangioma This striking histological feature assuming a periductal arrangement $[4,11,20,39-41]$.

\section{Management protocol}

Treatment of vasoformative tumors can be divided into three different approaches;

a. Conservative management with clinical monitoring,

b. Medically aggressive treatment or

c. Surgically invasive removal

Never the less, The therapeutic options for cavernous haemangiomas in adults are limited, Their treatment is exclusively surgical $[1,3,19,42]$ opposite of infantile haemangiomas that can be treated medically with a variety of options as endovascular sclerotherapy ,intralesional or systemic corticosteroids, vincristine and propanolol, intra-lesional alcohol injection, interferon , cryotherapy, laser surgery, vascular ligation, laser photocoagulation \& compression therapy followed cavernous hemangioma do not regress unlike most infantile hemangioma which resolve spontaneously, there is an inclination to avoid conservative treatment and go for surgical options, still there is few exceptional adult cases where conservative medical treatment with clinical monitoring is a better option as in patients unfit for surgery $[1,3,14,42,43]$. Sclerosing agents such as ethanol, ethanol amine oleate, sotradecol, tetradecyl sodium sulphate, ethanol and bleomycin hydrochloride can be injected percutaneously under radiological guidance [23,44-46].

Surgical resection and sclerotherapy are associated with a risk of facial nerve injury, which is increased in the case of very large lesion situated adjacent to the facial nerve, which can be difficult to precisely assess preoperatively. The patient must always be informed about the risk of this complication [23].

Super Selective pre-surgical embolization (a procedure performed by interventional radiologist that allows the improvement performance of subsequent surgery interventions , \& that are constantly evolving into standalone therapeutic modalities) is suggested 24-72 hours before surgery to decrease the risk of extensive intraoperative bleeding \& reduce tumor vasculature $[1,3,4,10,28,47]$, especially in cases where the hemangioma is extensive or the supplying vessel is a major one, that's why Before surgery, the vascular supply of the tumor a thorough imaging study by angio MRI (MRA) aimed at detecting the vascular supply (main \& collateral) should be analyzed in order to avoid intraoperative bleeding complications $[3,24,48,49]$. For small lesions, surgical excision poses little difficulty, in extensive lesions the facial nerve may be difficult to identify and should be monitored intraoperatively [3]. In general, more aggressive treatment is particularly considered when parotid hemangiomas are: large, deforming, ulcerated or involve neighboring structures, with functional consequences [24] (Figure 1).

Currently, the established documented clinical practice in the Adult cavernous intraparotid hemangioma in adults is surgery: partial or total parotidectomy according to level of involvement, using modified blair incision or modified face lift incision which give better aesthetic results, taking into consideration a presurgical super selective embolization 24-72 hours before surgery, with or without intraoperative supplying vessel ligation \& facial nerve preservation $[1,4,10,11,19,45]$.

Moreover, Xie et al. [50] introduced a minimally invasive endoscopic approach via a small preauricular incision performed on 5 patients with benign APG tumors and no postoperative complications and recurrences were found.

SS Intra-arterial Embolization can be done with: Temporary materials; Gelfoam, collagen, Iodine oil, or Perminant materials; butyl cyanoacrylate (NBCA), Ethiodol (iodine \& poppyseed), acrylic glue (Glubran), stainless steel, silky threads [4,24,51].

\section{Associated syndromes}

Several syndromes may be associated with cavernous hemangiomas, Kasabach-Merritt syndrome (large cavernous hemangioma associated with thrombocytopenic purpura, intravascular coagulation and platelet sequestration in the tumor) is the most severe $[3,17,41]$.

\section{Etiology}

Hemangiomas may arise from the gland proper or by invasion of subcutaneous blood vessels into the gland structure. Since Scarcella et al. [52] which is one of the oldest reports of cavernous hemangioma of the parotid gland in adults, the etiology of the disease was a point of great controversy [19]. It's considered benign proliferations of vessels closely resembling normal vessels, Marx et al. [48] argued that similarity to normal vessels is so great that it is unclear whether they represent vessel malformations, true neoplasms, or hamartomatous overgrowths $[4,17,48]$.

But, with the advancement in genetic study, the etiology of hemangioma is still elusive. Controversies surround all explanation from gene mutation to developmental factors for etiopathogenesis of hemangioma. Few evidences demonstrate that dendritic cells play an important role in the formation of hemangioma through some cytokine, such as vascular endothelial growth factor while some experts concluded that hemangioma originates from embryo of angioblasts $[4,36]$

Recently, the expression of cyclooxygenase 2 (COX2) protein on endothelial cells of several vascular spaces of cavernous hemangioma have been found but has little evidence with the relationship of vascular tumors. However, there has been reported that high doses of celecoxib have inhibited the cell proliferation of angiosarcomas cell lines. So, it could be considered as a new therapeutic line research for tumors of vascular origin $[1,3,4,8,53]$. 


\section{Advances in Dentistry \& Oral Health}

It is currently believed that hemangiomas are benign and congenital neoplasms, which are usually congenital or subclinical at birth undetected for long periods of time until sudden growth years later induces pain or cosmetic deformity (e.g., hereditary hemorrhagic telangiectasia and several facial hemangiomas) $[15,48]$.

\section{Conclusion}

Cavernous hemangioma of the parotid gland in adults is a rare benign pathology. Nevertheless, it should be included within the differential diagnosis of salivary gland swellings. Definitive diagnosis although difficult, it can be accomplished through clinical and radiographic findings. Through enlightening clinicians to the clinical presentations and examination methods to diagnose a parotid hemangioma, more cases will be recognized. We hope to encourage a group of leading pioneers to experiment with this information and document their findings, which may widen our data regarding the prevalence and etiology of the disease. The current unified management is surgery: partial or total parotidectomy according to level of involvement, using Modified Blair incision or Modified Face Lift incision, taking into consideration a pre-surgical super selective embolization if possible, with or without intraoperative supplying vessel ligation $\&$ facial nerve preservation is proven to be successful caring no complications.

\section{References}

1. Lara Sánchez H, Peral Cagigal B, Madrigal Rubiales B, Verrier Hernández A (2014) Cavernous Hemangioma of the Parotid Gland in Adults. J Clin Exp Dent 6(5): 592-594.

2. Gampper TJ, Morgan RF (2002) Vascular anomalies: hemangiomas. Plast Reconstr Surg 110: 572-585.

3. Halwani C, Zgolli C, Tbini M, Ben M hamed R, Akkari K (2018) Cavernous intra parotid hemangioma: a rare etiology of parotid tumors. J TUN ORL p: $1-3$.

4. Suwal R, Guan J, Wang XY, Khatri KS, Nyimi BF (2017) A Rare Case Report of Parotid Cavernous Hemangioma in an Adult. BJMMR 19(5): $1-5$.

5. Ponniah I, SureshKumar P, Karunakaran K, Shankar KA, Kumaran MG, et al. (2006) Hemangioma in minor salivary glands: Real or illusion. Diagnostic Pathology 1(1): 21.

6. Chahine KN, Tohme SM, Chouairy CJ (2007) Cavernous hemangioma of the parotid gland. J Med Liban 55(3): 165-166.

7. Mantadakis E, Emmanouela T, Savas D, Vassilios D, Athanassios C (2012) Involution of a large parotid hemangioma with oral propranolol: An illustrative report and review of the literature. Case Rep Pediatr p: 5.

8. Childers EL, Furlong MA, Fanburg-Smith JC (2002) Hemangioma of the salivary gland: a study of ten cases of a rarely biopsied /excised lesion. Ann Diagn Pathol 6(6): 339-344.

9. Choi HJ, Lee JC, Kim JH, Lee YM, Lee HJ (2013) Cavernous hemangioma with large phlebolith of the parotid gland. J Craniofac Surg 24(6): 621623.

10. World Health Organization Classification of Tumors (2005). International Agency for Research on Cancer In: Barnes L, Eveson JW Reichart P, Sidransky D (Eds.) Pathology and Genetics of Head and Neck Tumours. Lyon: IARC Press.

11. Achache M, Fakhry N, Varoquaux A, Coulibaly B, Michel J, et al. (2013)
Management of vascular malformations of the parotid area. Eur Ann Otorhinolaryngol Head Neck Dis 130(2): 55-60.

12. Mulligan PR, Prajapati HJ, Martin LG, Patel TH (2014) Vascular anomalies: Classification, imaging characteristics and implications for interventional radiology treatment approaches. Br J Radiol 87(1035): 20130392.

13. Wassef M, Blei F, Adams D, Alomari A, Baselga E, et al. (2015) Vascular anomalies classification: Recommendations From the international society for the study of vascular anomalies. Pediatrics 136(1): 203-214.

14. Emsen IM (2008) Preoperative treatment of a parotid hemangioma with 100\% ethyl alcohol. Can J Plast Surg 16(4): 239-240.

15. Chuang CC, Lin HC, Huang CW (2005) Submandibular Cavernous Hemangiomas with Multiple Phleboliths Masquerading as Sialolithiasis. J Chin Med Assoc 68(9): 441-443.

16. Nagao K, Matsuzaki O, Shigematsu H, Kaneko T, Katoh T, et al. (1980) Histopathologic studies of benign infantile hemangioendothelioma of the parotid gland. Cancer 46(10): 2250-2256.

17. Elsayed SA, Alahmady HH (2014) Heamangioma in parotid gland encroaching on the temporomandibular joint: A case report. Tanta Dental Journal 11(2): 109-113

18. Yadav JS, Chouhan M, Mody R, Bakhsi J (2011) Heamangioma of submandibular gland a rare case report entity. Int J Pediatr Otorhinolaryngol 6: 189-191.

19. Moses Nussbaum, Sergio Tan, Maxil Som (1977) Hemangioma of the Salivary Glands: Five salivary hemangiomas reports. New York.

20. Mandel L, Surattanont F (2004) Clinical and imaging diagnoses of intramuscular hemangiomas: The wattle sign and case reports. Journal of Oral and Maxillofacial Surgery 62(6): 754-758

21. Reddi BR (2013) A clinical observation to diagnose parotid hemangioma. Indian J Surg 75(Suppl 1): 401-403.

22. Karabin JE (1951) Cavernous hemangioma of the parotid gland; report of a case Surgery 30(2): 367-370.

23. Hammoudi K, Morinière SM, Lauvin A (2015) Unusual parotid swelling: What is the diagnosis? European Annals of Otorhinolaryngology, Head and Neck diseases 132: 165-166.

24. Eugenia Popescu, Violeta Trandafir D, Negrn N Dobrin, Daniela Trandafi (2013) Hemangioma of the parotid gland: Case Report Rev Med Chir Soc Med Nat Iaci 117(1): 227-232.

25. Altman KW, Marchant FE, Ochs RH (1998) Parotid Cavernous Hemangioma in an Adult, Ear Nose Throat J 77: 122-124.

26. O’Riordan B (1974) Phleboliths and salivary calculi. British J Oral Surg 12(2): 119-131

27. Dempsey EF, Murley RS (1970) Vascular malformations simulating salivery gland disease. Br J Plast Surg 23(1): 77-84.

28. Petros Koltsidopoulos, Charalambos Skoulakis (2015) Intramuscular hemangioma with turkey wattle sign. CMAJ 187(4): 277.

29. Barnes L (2001) Tumors and tumor-like lesions of the soft tissue. In: Barnes L (Ed.) Surgical pathology of the head and neck. $2^{\text {nd }}$ edn p. 900901.

30. Wolf GT, Daniel F, Krause CJ (1985) Intramuscular hemangioma of the head and neck. Laryngoscope 95: 210-213.

31. Rai P, Setia S, Kalra N (2006) Intramuscular vascular malformation of the masseter muscle presenting with turkey wattle sign. Oral Surg Oral Med Oral Pathol Oral Radiol Endod 102(5): 618.

32. Saeed WR, Kolhe PS, Smith FW (1997) The 'turkey wattle' sign revisited: diagnosing parotid vascular malformations in the adult. $\mathrm{Br}$ J Plast Surg 50(1): 43-46. 
33. Thulasiraman V, Ramesh PTR, Cheralathan S (2010) Internal jugular phlebectasia as an incidental finding in cervical spine surgery. Indian J Ortho 44(4): 471-473

34. Jamal TH, Saeed MK (1994) A cavernous hemangioma of the parotid gland. Annals Saudi Med 14(3): 250-254

35. Chuong R, Donoff B (1984) Intraparotid hemangioma in an adult: Case report and review of the literature. Int J Oral Surg 13(4): 346-351.

36. Yang T (2014) Congenital tri-cavernous hemangiomas of the right buccal region, right accessory parotid gland and masseter muscle region. J Craniofac Surg 25(2): 678-680.

37. Serkan Güneyli, Naim Ceylan, Selen Bayraktaroğlu, Türker Acar, Recep Savaș (2014) Imaging findings of vascular lesions in the head and neck. Diagn Interv Radiol 20(5): 432-437

38. Baker LL, Dillon WP, Hieshima GB, Dowd CF, Frieden IJ (1993) Hemangiomas and vascular malformations of the head and neck: MR characterization. Am J Neuroradiol 14(2): 307-314.

39. Tisch M (2005) Cavernous hemangioma of the parotid gland in adults. HNO 53(10): 879-883.

40. Yang $\mathrm{T}$ (2014) Congenital tri-cavernous hemangiomas of the right buccal region, right accessory parotid gland and masseter muscle region. J Craniofac Surg 25(2): 678-680.

41. Calonje E, Fletcher C (1995) Tumors of blood vessels and lymphatics. In: Diagnostic histopathology of tumors. CDM Fletcher (Ed.) Churchill Livingstone, Edinburgh 1: 43-77.

42. Weiss I, O TM, Lipari BA, Meyer L, Berenstein A, et al. (2011) Current Treatment of Parotid Hemangiomas, Laryngoscope. 121: 1642-1650.

43. Righini CA, Berta E, Atallah I (2014) Intramuscular cavernous hemangioma arising from the masseter muscle. European Annals of Otorhinolaryngology, Head and Neck Diseases 131(1): 57-59.

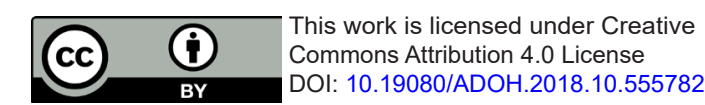

44. Bhandarwar AH, Utture SS, Shaikh A, Nandu B, Agarkhedkar N (2008) A Rare case Report of Parotid Haemangioma in a Child Treated by Sclerotherapy Using Bleomycin. Bombaiy Hospital J 50(4): 672-675.

45. Esposito C, Zupi A, Califano L (2000) Surgical therapy of parotid hemangiomas. Pediatr Surg Int 17(5-6): 335-337.

46. Chantharatanapiboon W (2008) Intralesional Corticosteroid Therapy in Hemangiomas: Clinical Outcome in 160 Cases. J Med Assoc Thai 91 (suppl 3): S90-S96.

47. Watzinger F (1997) Extensive facial vascular malformations and haemangiomas: A review of the literature and case reports. Journal of Cranio-Maxillofacial Surgery 25(6): 335-343.

48. Marx DS, Robert E (2003) Oral and maxillofacial pathology: a rationale for diagnosis and treatment. $1^{\text {st }}$ edn. 528. Hong Kong.

49. Hamdan AL, Hadi U, Moukarbel RV, Younes A, Tawil A (2001) Arteriovenous malformation of the parotid gland: Case report and review of the literature. Oto-Rhino-Laryngologia 11: 214-217

50. Xie L, Zhang D, Lu MM, Gao BM (2012) Minimally invasive endoscopicassisted resection of benign tumors in the accessory parotid gland: 5 case studies. Head Neck 34(8): 1194-1197.

51. Langdon JD, Patel MF (2016) Operative Oral and Maxillofacial Surgery. $3^{\text {rd }}$ Edition 500-505.

52. Scarcella JV, Dykes ER, Anderson R (1965) Hemangioma of the parotid hland. Plast And Reconstruct Surg 36: 38-47.

53. Ratour J, Benzakin S, Handra-Luca A (2013) Adult sporadic parotid hemangioma with COX2 Expression. J Craniofac Surg 24(6): 2211 2212 .

\section{Your next submission with Juniper Publishers will reach you the below assets}

- Quality Editorial service

- Swift Peer Review

- Reprints availability

- E-prints Service

- Manuscript Podcast for convenient understanding

- Global attainment for your research

- Manuscript accessibility in different formats

( Pdf, E-pub, Full Text, Audio)

- Unceasing customer service

Track the below URL for one-step submission

https://juniperpublishers.com/online-submission.php 